\title{
Efficacy of different concentrations of sodium hypochlorite and chlorhexidine in disinfection of contaminated Resilon cones
}

\author{
Vahid Zand ${ }^{1}$, Amin Salem-Milani ${ }^{2}$, Shahriar Shahi ${ }^{3}$, Mohammad-Taghi Akhi ${ }^{4}$, Siamak Vazifekhah ${ }^{5}$
}

${ }^{1}$ DDS, MSc, Assistant Professor, Department of Endodontics, Faculty of Dentistry, Tabriz University of Medical Sciences, Tabriz, Iran

${ }^{2}$ DDS, MSc, Assistant Professor, Dental and periodontal disease research center, Faculty of Dentistry, Tabriz University of Medical Sciences, Tabriz, Iran

${ }^{3}$ DDS,MSc, Associate Professor, Dental and periodontal disease research center, Faculty of Dentistry, Tabriz University of Medical Sciences, Tabriz, Iran

${ }^{4} \mathrm{PhD}$, Associate professor of Medical Microbiology Department, Tabriz University of Medical Sciences

${ }^{5}$ DDS, Dentist

Correspondence:

Department of Endodontics,

Faculty of Dentistry, Golgasht Street,

Tabriz, Iran

Amin_salemmilani@hotmail.com

Received: 05/01/2011

Accepted: 09/04/201

Zand V, Salem-Milani A, Shahi S, Akhi MT, Vazifekhah S. Efficacy of different concentrations of sodium hypochlorite and chlorhexidine in disinfection of contaminated Resilon cones. Med Oral Patol Oral Cir Bucal. 2012 Mar 1;17 (2):e352-5.

http://www.medicinaoral.com/medoralfree $01 / \mathrm{v} 17 \mathrm{i} 2 /$ medoralv17i2p352.pdf

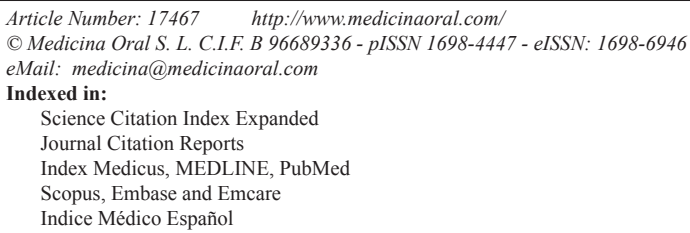

\begin{abstract}
Objectives: The aim of this study was to evaluate the effectiveness of different concentrations of Chlorhexidine (CHX) and sodium hypochlorite $(\mathrm{NaOCl})$ in disinfecting contaminated Resilon cones within one minute.

Study design: Fifty Resilon cones were divided into seven experimental groups and three control groups of 5 cones each. The cones of experimental groups were contaminated with Entrococcus faecalis and subsequently disinfected with different concentrations of $\mathrm{NaOCl}$ or $\mathrm{CHX}$. The cones were then transferred into glass tubes containing thioglycollate media and incubated for 7 days. The tubes were examined for turbidity every 24 hours, and if bacterial growth occurred, samples were plated, incubated, gram stained and observed under microscope to confirm E. faecalis growth. Negative, positive, and washing control groups were also used.

Results: All the positive and washing control showed profound E.faecalis growth. All the cones disinfected with CHX showed bacterial growth; however, no E. faecalis growth occurred in any samples disinfected with $\mathrm{NaOCl}$. Conclusion: Sodium hypochlorite, at concentrations of 0.5 to $5.25 \%$, is an effective agent for disinfection of contaminated Resilon cones within one minute; however, chlorhexidine is unable to disinfect Resilon cones during one-minute exposure.
\end{abstract}

Key words: Chlorhexidine, sodium hypochlorite, resilon, entrococcus faecalis. 


\section{Introduction}

Microorganisms are the main etiologic factor of pulp and periapical pathosis (1). Thus, the primary goal of endodontic treatment is the elimination of microorganisms from infected root canals and prevention of their re-entry. For this purpose, every phase of endodontic therapy should be performed under aseptic conditions.

Resilon (Pentron Clinical Technologies LLC, Wallingford, CT) is a thermoplastic polycaprolactonebased root canal material which is similar to guttapercha in many properties such as size, color, and handling (2). Resilon is used with a resin-based sealer, Epiphany, and according to the manufacturer, forms a "monoblock" within the canal. Several studies have shown that this "monoblock" has less microleakage than gutta-percha fillings and strengthens the tooth structure $(2,3)$. Gutta-percha and Resilon cones are produced under aseptic conditions; however, they can be contaminated by aerosols and physical sources during storage (4-6). Even if the cones are carefully removed from the package, they may become infected with microorganisms by handling (6-8). Guttapercha and Resilon cones can not be disinfected with routine heat sterilization methods; therefore, an alternative rapid disinfection approach is desirable. Different chemicals have been proposed for rapid chemical disinfection of gutta-percha cones. Sodium hypochlorite $(\mathrm{NaOCl})$, as the most common irrigating solution, has been used in several studies to disinfect contaminated gutta-percha or Resilon cones (7-12). The results were dependent on the concentration of $\mathrm{NaOCl}$ and exposure time (5). Chlorhexidine (CHX), as another endodontic irrigant, is a broad-range disinfectant which is effective against most bacteria and yeasts found in endodontic infections. CHX has also been used in some studies to disinfect gutta-percha or Resilon cones with contradictory results regarding the most proper time and concentration of CHX or $\mathrm{NaOCl}$ to disinfect contaminated Resilon cones. Dumani et al. (12) found that $2 \% \mathrm{CHX}$ is not effective in disinfection of Resilon cones at one-minute exposure. However, Gomes and Royal et al. showed that $2 \% \mathrm{CHX}$ is an effective agent in eliminating Entrococcus faecalis even within 15 seconds $(5,7)$. All these studies have used 2\% CHX, and there is no published study on the efficacy of the different concentrations of CHX. Because of this controversy, the present study was designed to evaluate the effectiveness of different concentrations of $\mathrm{NaOCl}$ and $\mathrm{CHX}$ in rapid disinfection of contaminated Resilon cones.

\section{Materials and methods}

Fifty Resilon cones (Pentron Clinical Technologies LLC, Wallingford, CT) were divided into seven experi- mental groups and three control groups of 5 cones each. The method of the experiment has been summarized in (Fig. 1). The cones were disinfected with UV light (250 microW/cm2) for 20 minutes. The experimental cones were immersed in $20 \mathrm{ml}$ of microbial suspension of 108 CFU/ml Entrococcus faecalis (E. faecalis) ATCC29212 in Trypticase soy broth for 30 minutes and then transferred into Petri dishes and allowed to dry for 10 minutes at room temperature. Then, cones of each experimental group were immersed in separate Petri dish containing $20 \mathrm{ml}$ of the disinfectants with different concentrations for one minute. The experimental groups were as follows: groupl: $0.5 \% \mathrm{NaOCl}$, group 2: $1 \% \mathrm{NaOCl}$, group 3: $2.5 \% \mathrm{NaOCl}$, group 4: $5.25 \% \mathrm{NaOCl}$, group 5: $0.5 \%$ CHX, group 6: $1 \%$ CHX, group 7: $2 \%$ CHX. The cones of experimental groups were then immersed in detergent (3\% Tween 80 plus 5\% sodium thiosulfate) for 5 minutes and washed with $10 \mathrm{ml}$ of sterile distilled water. The cones were separately transferred into glass tubes containing $10 \mathrm{ml}$ of thioglycollate and incubated at 37 ${ }^{\circ} \mathrm{C}$ for 7 days. A blinded observer examined the tubes every 24 hours for turbidity which indicated bacterial growth in the tubes. At the end of 7 days, in the case of bacterial growth, $0.1 \mathrm{ml}$ of thioglycollate was inoculated into $10 \%$ blood agar and incubated at $37^{\circ} \mathrm{C}$ for 48 hours. The bacterial colonies in blood agar plates were the signs of bacterial growth. Gram staining and observation under light microscope were used to confirm that the bacteria were E. faecalis.

Three control groups were used as follows: In negative control, the cones were disinfected under UV and directly transferred into thioglycollate and examined for bacterial growth to check the primary sterility of the samples. In positive control, the cones were disinfected under UV, contaminated with E. faecalis similar to experimental groups and then transferred into thioglycollate and examined for bacterial growth to check the accuracy of contamination process. In the washing control group, the process was the same as experimental groups except that exposure to disinfectants was not carried out.

The number of growth positive samples in experimental or control groups were recorded and analyzed with descriptive statistical methods using SPSS software for windows (SPSS Inc, Chicago, IL).

\section{Results}

All the positive and washing control showed heavy turbidity and E. faecalis growth was confirmed by culturing and gram staining. No bacterial growth occurred in any negative control samples.

All the cones disinfected with various concentrations of CHX showed E. faecalis growth. However, no E. faecalis growth occurred in any samples disinfected with different concentrations of $\mathrm{NaOCl}$ (Table 1). 


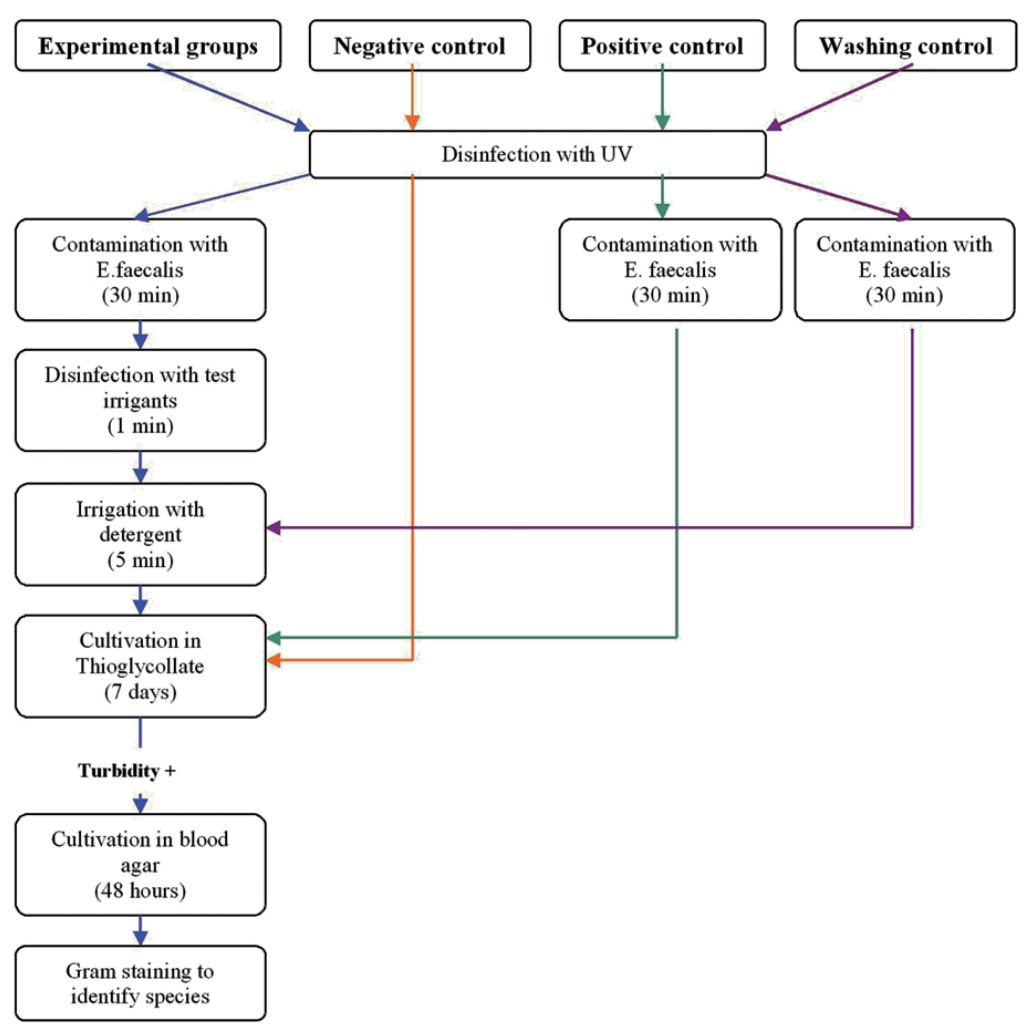

Fig. 1. Diagram representing the process of the study.

Table 1. Microbial growth of E. faecalis after disinfection with different concentrations of sodium hypochlorite $(\mathrm{NaOCl})$ and Chlorhexidine $(\mathrm{CHX})$.

\begin{tabular}{|l|c|c|}
\hline Groups & Number of samples & Number of positive growth samples \\
\hline Group1 $(\mathbf{0 . 5 \%}$ NaOCl) & 5 & 0 \\
\hline Group 2 (1 \% NaOCl) & 5 & 0 \\
\hline Group 3 (2.5\% NaOCl) & 5 & 0 \\
\hline Group 4 (5.25\% NaOCI) & 5 & 5 \\
\hline Group 5 (0.5\% CHX) & 5 & 5 \\
\hline Group 6 (1 \% CHX) & 5 & 5 \\
\hline Group 7 (2\% CHX) & 5 & 0 \\
\hline Negative control & 5 & 5 \\
\hline Positive control & 5 & 5 \\
\hline Washing control & 5 & 5 \\
\hline
\end{tabular}

\section{Discussion}

One of the causes of root canal reinfection is the use of contaminated root canal fillings (7). Gutta-percha or Resilon cones are manufactured under aseptic conditions; however, contamination may occur after removal from the package as a result of exposure to environment and by handling $(4-6,8)$. Therefore, rapid disinfection of
Resilon or gutta-percha cones prior to obturation is desirable. A chemical disinfection is appropriate because heat sterilization alters the properties of cones. $\mathrm{NaOCl}$ and CHX are two common endodontic irrigants and have been used in some studies with varying concentrations for chemical disinfection of root canal filling materials $(5,7,9-12)$. 
E. faecalis was chosen for this study because this species has been shown to be a predominant bacterial species in resistant endodontic cases $(13,14)$. E. faecalis has also been used in many studies on the efficacy of endodontic irrigants $(15,16)$.

In our study, $\mathrm{NaOCl}$ with $0.5 \%, 1 \%, 2.5 \%$ or $5.25 \%$ concentrations was effective in decontamination of Resilon cones. This is in accordance with the results of other studies $(5,7,10-12)$; however, our study showed that chlorhexidine is not effective in decontamination of Resilon cones within one minute. Similarly, Dumani et al. (12) found that 1 -min treatment with $2 \% \mathrm{CHX}$ is not sufficient to disinfect the Resilon cones, and it is effective only after 5-min treatment. However, Royal et al. (7) showed that one-min treatment with $2 \% \mathrm{CHX}$ is sufficient to disinfect contaminated gutta-percha or Resilon cones. Both of these studies used E. faecalis as test species and followed similar process except that Royal et al. (7) used Resilon pellets instead of cones because of easy handling, and the bacterial exposure time was $5 \mathrm{~min}$ in contrast to our study which used 30 min exposure. Regardless of these differences in methods and materials, these contradictory results need more investigation.

Gomes et al. (5) also showed that even $1 \% \mathrm{CHX}$ is effective within 15 seconds in decontamination of guttapercha cones. It's difficult to compare the results of our study with the results of studies on gutta-percha because Resilon and gutta-percha have different chemical composition and surface texture (12). In addition, unlike Resilon, gutta-percha has antimicrobial property which may be an explanation for the less time required to disinfect gutta-percha cones by $\mathrm{CHX}$ than Resilon cones $(17,18)$.

We recommend that this study be repeated with other bacterial species, different forms of Resilon (cones or pellets), and varying bacterial exposure times. Blindness of the examiners is another important factor that may influence the results of the study and is recommended to be taken into consideration in future studies.

\section{Conclusion}

Sodium hypochlorite, at concentrations of 0.5 to $5.25 \%$, is an effective agent for disinfection of contaminated Resilon cones within one minute; however, chlorhexidine is unable to disinfect Resilon cones during 1-min exposure.

\section{References}

References with links to Crossref - DOI

1. Kakehashi S, Stanley HR, Fitzgerald RJ. The effects of surgical exposures of Dental pulps in germ-free and conventional laboratory rats. Oral Surg Oral Med Oral Pathol. 1965;20:340-9.

2. Shipper G, Orstavik D, Teixeira FB, Trope M. An evaluation of microbial leakage in roots filled with a thermoplastic synthetic polymerbased root canal filling material (Resilon). J Endod. 2004;30:342-7.

3. Teixeira FB, Teixeira EC, Thompson JY, Trope M. Fracture resistance of roots endodontically treated with a new resin filling material. $\mathrm{J}$ Am Dent Assoc. 2004;135:646 -52.

4. Da Motta PG, de Figueiredo CB, Maltos SM, Nicoli JR, Ribeiro
Sobrinho AP, Maltos KL, et al. Efficacy of chemical sterilization and storage conditions of gutta-percha cones. Int Endod J. 2001;34:435-9. 5. Gomes BP, Vianna ME, Matsumoto CU, Rossi Vde P, Zaia AA, Ferraz $\mathrm{CC}$, et al. Disinfection of gutta-percha cones with chlorhexidine and sodium hypochlorite. Oral Surg Oral Med Oral Pathol Oral Radiol Endod. 2005;100:512-7.

6. Isci S, Yoldas O, Dumani A. Effects of sodium hypochlorite and chlorhexidine solutions on Resilon (synthetic polymer based root canal filling material) cones: an atomic force microscopy study. J Endod. 2006;32:967-9.

7. Royal MJ, Williamson AE, Drake DR. Comparison of 5.25\% sodium hypochlorite, MTAD, and $2 \%$ chlorhexidine in the rapid disinfection of polycaprolactone-based root canal filling material. J Endod. 2007;33:42-4.

8. Linke HA, Chohayeb AA. Effective surface sterilization of guttapercha points.Oral Surg Oral Med Oral Pathol. 1983;55:73-7.

9. Stabholz A, Stabholz A, Friedman S, Heling I, Sela MN. Efficiency of different chemical agents on decontamination of gutta-percha cones. Int Endod J. 1987;20:211-6.

10. Senia ES, Marraro RV, Mitchell JL, Lewis AG, Thomas L. Rapid sterilization of gutta-percha cones with $5.25 \%$ sodium hypochlorite. $\mathrm{J}$ Endod. 1975;1:136-40.

11. Siqueira JF Jr, da Silva CH, Cerqueira M das D, Lopes HP, de Uzeda M. Effectiveness of four chemical solutions in eliminating Bacillus subtilis spores on gutta-percha cones. Endod Dent Traumatol. 1998:14:124-6.

12. Dumani A, Yoldas O, Isci AS, Köksal F, Kayar B, Polat E. Disinfection of artificially contaminated Resilon cones with chlorhexidine and sodium hypochlorite at different time exposures.Oral Surg Oral Med Oral Pathol Oral Radiol Endod. 2007;103:e82-5.

13. Molander A, Reit C, Dahlen G, Kvist T. Microbial status of rootfilled teeth with apical periodontitis. Int Endod J. 1998;31:1-7.

14. Sundqvist G, Figdor D, Persson S, Sjögren U. Microbiologic analysis of teeth with failed endodontic treatment and the outcome of conservative re-treatment. Oral Surg Oral Med Oral Pathol Oral Radiol Endod. 1998;85:86-93.

15. Ayhan H, Sultan N, Çirak M, Ruhi MZ, Bodur H. Antimicrobial effects of various endodontic irrigants on selected microorganisms. Int Endod J. 1999;32:99-102.

16. Shih M, Marshall FJ, Rosen S. The bactericidal efficiency of sodium hypochlorite as an endodontic irrigant. Oral Surg Oral Med Oral Pathol. 1970;29:613-9.

17. Moorer WR, Genet JM. Evidence for antibacterial activity of endodontic gutta-percha cones.Oral Surg Oral Med Oral Pathol. 1982;53:503-7.

18. Melker KB, Vertucci FJ, Rojas MF, Progulske-Fox A, Bélanger M. Antimicrobial efficacy of medicated root canal filling materials. J Endod. 2006;32:148-51. 